\title{
Knowledge, Attitude, and Practice toward COVID-19 among UAE Residents: An Online Cross-Sectional Survey
}

\author{
Lubna Lutfi $^{\mathrm{a}}$ Alma AlMansour ${ }^{\mathrm{b}}$ AlReem AlMarzouqi ${ }^{\mathrm{b}}$ Syeda Hira Hassan ${ }^{\mathrm{b}}$ \\ Zainab Salman $^{\mathrm{b}}$ Hiba Hamad $^{\mathrm{b}}$ Samia Farghaly ${ }^{\mathrm{b}}$ Dina AlAjmanic \\ a Medical Internship Program, Dubai Health Authority, Dubai, UAE; ${ }^{\text {b} M e d i c i n e ~ C o l l e g e, ~ D u b a i ~ M e d i c a l ~ U n i v e r s i t y, ~}$ \\ Dubai, UAE; 'Department of Family Medicine, Dubai Health Authority, Dubai, UAE
}

\section{Keywords}

COVID-19 Knowledge, attitude, and practice $\cdot$ UAE population

\section{Abstract \\ Background: COVID-19 is an emerging respiratory virus which was initially reported to the WHO on December 31, 2019 and declared as a public health emergency by the WHO on March 11, 2020. Aim: The aim of the study was to investi- gate the public knowledge, attitudes, and practice toward COVID-19. Method: This is an online cross-sectional study. The questionnaire was in both Arabic and English languages and consisted of 4 segments (demographic, knowledge, at- titude, and practice). The results were collected anonymous- ly. The data were entered in Excel sheets and then exported and analyzed using SPSS software. Results: A total of 1,602 UAE residents completed the questionnaire. The mean knowledge score is $71 \%$, which reflects good knowledge. The mean attitude score is $78 \%$, which reflects a positive at- titude. The mean practice score is $76 \%$, which reflects good practice. Ninety-four percent of the population avoid hand-}

karger@karger.com www.karger.com/dmj

Karger $\stackrel{\text { ' }}{5}$
(C) 2021 The Author(s)

Published by S. Karger AG, Basel

This is an Open Access article licensed under the Creative Commons Attribution-NonCommercial-4.0 International License (CC BY-NC) (http://www.karger.com/Services/OpenAccessLicense), applicable to the online version of the article only. Usage and distribution for commercial purposes requires written permission. shakes, $93.3 \%$ wear face masks regularly, $85.5 \%$ use hand sanitizers, and $66 \%$ wash their hands, $22.7 \%$ drink honey with ginger, $13 \%$ still prefer to take garlic, and $82 \%$ chose to constantly update themselves with information about COVID-19; however, only $10 \%$ relied on purely medical sources. Conclusions: This study showed that UAE residents have satisfactory knowledge and favorable practice, with an overall high positive attitude. However, it is still encouraged to continue efforts in spreading awareness and public health education across all platforms, as well as increase awareness campaigns and correct misconceptions circulating on nonmedical platforms since they are a major source of information for the public.

(c) 2021 The Author(s)

Published by S. Karger AG, Basel

\section{Introduction}

COVID-19 is an emerging respiratory virus that has caused a global pandemic, claiming its spot as one of the deadliest pandemics in the 21st century. COVID-19 or SARS-CoV-2 was first diagnosed amid an outbreak of re- 
spiratory illness cases in Wuhan city, Hubei Province, China. It was initially reported to the WHO on December 31,2019 . In 2020, the WHO declared the outbreak a global health emergency. On March 11, 2020, the WHO declared COVID-19 a global pandemic, the first designation since declaring H1N1 influenza a pandemic in $2009[1,2]$. The first confirmed cases of COVID-19 in the UAE emerged in February 2020 [3].

COVID-19 descends from a large family of viruses that cause a spectrum of respiratory diseases, common cold being the mildest to respiratory failure being the more severe complication of the disease. In the UAE, as of July 2020, there have been 57,988 diagnosed cases and 342 deaths, bringing the case fatality rate to $<0.1[4]$.

The battle against COVID-19 is still continuing in the UAE. To guarantee the final success, people's adherence to preventive control measures is essential, which is largely affected by their knowledge, attitudes, and practices (KAP) toward COVID-19 in conformance to the KAP theory. To facilitate the outbreak management of COVID-19 in the UAE, there is an urgent need to understand the public awareness of COVID-19 at this critical moment. In this study, we investigated the KAP toward COVID-19 of UAE residents during the rapid rise period of the COVID-19 outbreak. As the most prominent theory suggests having been transmitted from a bat, the virus has spread faster than the mammal could spread its wings and found itself landing internationally, rather unwelcomed.

\section{Methods}

Study design: This study was conducted as an online cross-sectional study in the UAE during the COVID-19 outbreak in 2020 from 31 May 2020 to 13 June 2020. The study targeted the general population.

Study procedure: The study was conducted online with a survey in both English and Arabic formats. Participants were all UAE residents, and any candidates who were non-UAE residents were excluded. All participants were older than 16 years and were literate. These inclusions were made to keep the study limited to learning the KAP toward COVID-19 among UAE residents only. The sample size of this online cross-sectional study was calculated using a confidence level of $95 \%$ and a margin of error of $5 \%$, with a population prevalence of $50 \%$. The sample size was a minimum of 384. All participants were ensured anonymity and confidentiality as instructed by the Research Ethical Committee, Dubai Health Authority.

Survey design (evaluation tools): The questionnaire and consent form were uploaded in Google Forms. Links for the surveys were spread to the general population through social media platforms, namely, WhatsApp, Facebook, and Instagram. The ques- tionnaire was referenced in our literature review. This questionnaire aimed to evaluate the KAP of residents of the UAE toward COVID-19. The questionnaire covers 4 segments: demographics, knowledge, attitude, and practice. The demographics segment includes age, gender, nationality, marital status, occupation, and level of education. Knowledge segment questions cover the type of infection, the symptoms of the infection, the route of transmission, susceptibility, and the availability of treatment and vaccination.

Attitude segment questions cover capability of enduring future public health emergencies, meeting someone cured from $\mathrm{CO}$ VID-19, and the ability to control the pandemic globally and locally in the UAE. Practice segment questions cover preventive practices, response to getting the infection or having a close contact with a confirmed case, and keeping up to date with news and the source of that.

The knowledge segment includes 6 questions. A scoring system was used by which a score of one is given to each correct answer and 0 to each incorrect answer. Then, the total knowledge score of 6 for each participant was converted to percent (by dividing by 6 and multiplying by 100) to represent the participants' percent knowledge score.

The attitude segment includes 4 questions. A score of one was given to positive attitude responses, and a score of zero was given to each negative attitude response. The total attitude score was then converted to a percent attitude score. The practice segment includes 6 questions. Similarly, a score of one was given to each correct practice, and a score of zero was given to each incorrect practice. The total practice score was then converted to a percent practice score. The mean knowledge, mean attitude, and mean practice scores were calculated by obtaining the sum of values and then dividing it by the total number of responses.

Demographics includes nationality, gender, age-group, marital status, occupation, and level of education. Knowledge includes the type of infection, mode of transmission, symptoms, treatment and vaccination, and susceptible group. Attitude determines are UAE residents more capable to endure such public health emergencies in the future, would they meet someone who was cured from COVID-19, do they think the epidemic will be controlled, and whether they trust the local authorities' efforts to control it. Practice determines do UAE residents practice the preventive measures, what would they do if they develop symptoms, what would they do in case of contact, have they been to a crowded place recently, and are they following the news.

The questionnaire underwent translation and back-translation by professionals and was in both English and Arabic formats. A pilot study was conducted, through which 60 responses were collected from the general population. The feedback from the responses was taken into consideration by editing some of the elements in the survey.

\section{Statistical Data and Analysis}

The data are presented as means and SD for numerical variables and count (\%) for the categorical variables. The $\chi^{2}$ test was used to test the association between the groups of participants and the categories of different responses. A $p$ value $<0.05$ indicates statistical significance. SPSS 24 is used for statistical analysis (IBM SPSS Statistics for Windows, version 24.0.; IBM Corp., Armonk, NY, USA) 
Table 1. Descriptive demographic characteristics of participant $(n=1,602)$

\begin{tabular}{lc}
\hline & $N(\%)$ \\
\hline $\begin{array}{l}\text { Nationality } \\
\text { Local }\end{array}$ & $730(45.6)$ \\
Gender & \\
$\quad$ Female & $1,402(88)$ \\
Age, years & $1,178(73.5)$ \\
16-29 & $315(19.7)$ \\
$30-49$ & $109(6.8)$ \\
50 or more & \\
Marital status & $554(34.6)$ \\
$\quad$ Married & $1,024(63.9)$ \\
$\quad$ Not married & $24(1.5)$ \\
Other & \\
Education & $1,268(79.2)$ \\
College & $331(20.7)$ \\
High school & $3(0.2)$ \\
No school attended & \\
Occupation & \\
Healthcare-related & $406(25.3)$ \\
\hline
\end{tabular}

\section{Results}

\section{Social and Demographic Characteristics}

A total of 1,615 people completed the questionnaire. We excluded 13 responses of those who were living outside the UAE, and the final sample included 1,602 UAE residents. The social and demographic data of the participants were as follows: participants were mainly female, 1,402 (88\%), compared to only 200 (12\%) male respondents. $730(45.6 \%)$ of the participants were local residents, and $872(54.4 \%)$ were nonlocal residents. The majority, 1,178 (73.5\%), were between the ages of 16 and 29 years. Of all responses, 1,024 (63.9\%) were not married and $554(34.6 \%)$ participants were married. Most participants, 1,268 (79.2\%), were in or had completed college. In addition, more than half of the participants, 1,196 (74.7\%), worked in non-healthcare-related jobs, while only 406 (25.3\%) worked in healthcare-related jobs (Table 1).

A total of 6 questions were used to measure knowledge. The mean score was 4.2 , with an SD of 1.24, and the overall percent knowledge score was $71 \%$. Majority of the participants knew that COVID-19 is a viral infection, 1,507 (94.1\%) with the main route of transmission being respiratory droplets and close contacts 1,546 (96.5\%). 1,414 (88\%) participants identified the main symptoms of the infection included fever and cough. However, the percentage of participants knowing there is currently no specific treatment and no vaccine available (at the time the
Table 2. Assessing the knowledge toward COVID-19 in the UAE $(n=1,602)$

\begin{tabular}{lc}
\hline Respondents' knowledge question & $\begin{array}{l}\text { Correct } \\
\text { answer, } n(\%)\end{array}$ \\
\hline 1. What type of infection is COVID-19? & $1,507(94.1)$ \\
2. What is the main route of transmission? & $1,546(96.5)$ \\
3. The following are symptoms of COVID-19 & $1,414(88.3)$ \\
4. COVID-19 has no specific treatment & $927(57.9)$ \\
5. COVID-19 has no vaccine & $993(62)$ \\
6. Who are susceptible for COVID-19 infection? & $489(30.5)$ \\
\hline
\end{tabular}

survey was being conducted) was considerably lower, 927 (57.9\%) and 993 (62\%), respectively. Similarly, only 489 (30.5\%) participants answered that the population in general is susceptible for COVID-19 infection, whereas the remaining 1,113 (69.5\%) answered either "elderly" or "people with pre-existing diseases" (Table 2).

Assessing people's attitude was one of the objectives of the study because a positive attitude reflects the impact of public education. Statistics showed a positive attitude in every element. The percent attitude score was $78.3 \%$.

$1,176(73.4 \%)$ of the participants were confident that the COVID-19 pandemic will be successfully controlled. 1,399 (87.3\%) participants were confident that the UAE specifically is capable of controlling the virus within the country. When asked if they were more capable of enduring a public health emergency like this one in the future, 1,240 (77.4\%) participants answered "yes." Public education most probably has been a major contributor in spreading awareness, and that has manifested in the general public attitude. Finally, when the participants were asked what they would do if someone cured from COVID-19 wanted to meet them, 1,184 (Table 3) (73.9\%) said they would meet them and 418 (26.1\%) said they would find an excuse not to meet them. While the numbers for both meeting them and being nicer or meeting them and being the same were almost identical, only a minority said they would not meet a person cured from COVID-19 (Fig. 1). It is advisable by the WHO that a sick patient should continue social distancing till 2 weeks after the last symptom disappears since they can still infect others [3]. It is worth noting that the question does not specify taking precautionary measures during the meeting.

Furthermore, the questionnaire had 6 questions to assess the populations' practice. The questions asked the following: what they do to prevent the infection, what would they do if they ever experienced symptoms of the disease, what would they choose to do when in contact 
Table 3. Assessing the attitude toward COVID-19 in the UAE $(n=1,602)$

\begin{tabular}{|c|c|c|c|}
\hline Respondents' attitude question & Response, $n(\%)$ & & \\
\hline $\begin{array}{l}\text { Do you think you will be more capable to endure such public health } \\
\text { emergencies? }\end{array}$ & $\begin{array}{l}\text { Yes } \\
1,240(77.4)\end{array}$ & $\begin{array}{l}\text { I will be the same } \\
228(14.2)\end{array}$ & $\begin{array}{l}\text { No } \\
134(8.4)\end{array}$ \\
\hline $\begin{array}{l}\text { What would you do if someone cured of COVID-19 wanted to meet } \\
\text { you? }\end{array}$ & $\begin{array}{l}\text { I will meet them } \\
\text { and be nicer } \\
597(37.3)\end{array}$ & $\begin{array}{l}\text { I will meet them like } \\
\text { usual } \\
587(36.6)\end{array}$ & $\begin{array}{l}\text { I will find an excuse } \\
\text { not to meet them } \\
418(26.1)\end{array}$ \\
\hline Do you think that COVID-19 will finally be successfully controlled? & $\begin{array}{l}\text { Agree } \\
1,176(73.4)\end{array}$ & $\begin{array}{l}\text { I do not agree } \\
62(3.9)\end{array}$ & $\begin{array}{l}\text { Not sure } \\
364(22.7)\end{array}$ \\
\hline Do you have confidence that the UAE will successfully control it? & $\begin{array}{l}\text { Agree } \\
1,399(87.3)\end{array}$ & $\begin{array}{l}\text { I do not agree } \\
16(1.0)\end{array}$ & $\begin{array}{l}\text { Not sure } \\
187(11.7)\end{array}$ \\
\hline
\end{tabular}

Fig. 1. Association between age and attitude toward meeting someone cured from COVID-19.

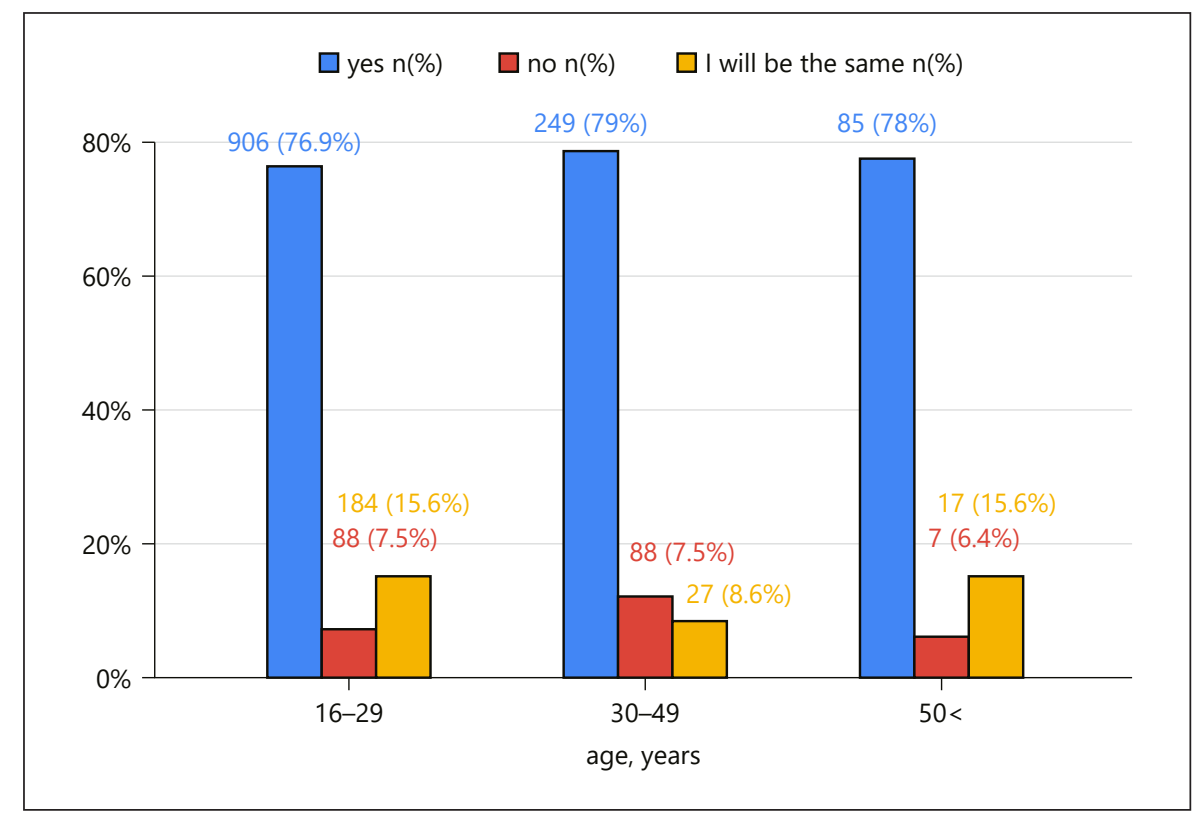

with a confirmed COVID-19 case, whether they have recently been to a crowded area, if they follow regular updates on COVID-19, and what their source is (Table 4).

The results regarding practices followed by the population during this pandemic have reflected maturity on an individual level, with 1,489 (94.2\%) of the population chose to avoid handshakes, $1,375(87.0 \%)$ used hand sanitizers, 1,515 (95.8\%) washed their hands regularly, and $1,495(94.6 \%)$ participants wore face masks. Nonetheless, the belief in herbal medicine still plays a role in today's health practices; the results showed that $213(13.5 \%)$ individuals preferred to take garlic and 363 (23.0\%) others would drink honey with ginger.
Another aspect evaluated was the population's response if they experienced any respiratory symptoms mimicking those of COVID-19. 1,475 (93.2\%) participants chose to analyze the situation rationally and stay home for observation and quarantine or go to the hospital for treatment.

Additionally, the populations' response if they ever came into contact with a confirmed case was also evaluated; $1,511(95.5 \%)$ opted to report their cases to the health authority. Also, 1,365 (86\%) opted to avoid going to crowded places.

Finally, when asked about being updated with COVID-19 news, 1,311 participants (82.9\%) replied that they kept themselves up to date. 1,000 (62.4\%) respondents 
Table 4. Assessing the practice toward COVID-19 in the UAE $(n=1,602)$

\begin{tabular}{|c|c|c|c|}
\hline Respondents' practice question & Response, $n(\%)$ & & \\
\hline A. I avoid hand shaking & $\begin{array}{l}\text { Yes } \\
1,489(94.2)\end{array}$ & $\begin{array}{l}\text { No } \\
113(5.8)\end{array}$ & \\
\hline B. I wash my hands & $\begin{array}{l}\text { Yes } \\
1,515(95.8)\end{array}$ & $\begin{array}{l}\text { No } \\
87(4.2)\end{array}$ & \\
\hline C. I use alcoholic hand rub & $\begin{array}{l}\text { Yes } \\
1,375(87.0)\end{array}$ & $\begin{array}{l}\text { No } \\
227 \text { (13) }\end{array}$ & \\
\hline D. I cough and sneeze in a tissue and throw it in waste bin & $\begin{array}{l}\text { Yes } \\
1,179(74.6)\end{array}$ & $\begin{array}{l}\text { No } \\
423(25.4)\end{array}$ & \\
\hline E. I wear a face mask & $\begin{array}{l}\text { Yes } \\
1,495(94.6)\end{array}$ & $\begin{array}{l}\text { No } \\
107(5.4)\end{array}$ & \\
\hline F. I drink ginger with honey & $\begin{array}{l}\text { Yes } \\
363(23.0)\end{array}$ & $\begin{array}{l}\text { No } \\
1,239 \text { (77) }\end{array}$ & \\
\hline G. I eat garlic & $\begin{array}{l}\text { Yes } \\
213(13.5)\end{array}$ & $\begin{array}{l}\text { No } \\
1,389(86.5)\end{array}$ & \\
\hline 2. Have you gone to any crowded places in the recent days? & $\begin{array}{l}\text { Yes } \\
217(13.7)\end{array}$ & $\begin{array}{l}\text { No } \\
1,385(86.3)\end{array}$ & \\
\hline 3. Do you follow regular updates on the virus? & $\begin{array}{l}\text { Yes } \\
1,311(82.9)\end{array}$ & $\begin{array}{l}\text { No } \\
291(17.1)\end{array}$ & \\
\hline 4. What would you do if you had fever and dry cough? & $\begin{array}{l}\text { I want to go to the hospital but I am scared } \\
\text { OR I don't know what to do } \\
107(6.8)\end{array}$ & $\begin{array}{l}\text { I will think logically } \\
1,475(93.2)\end{array}$ & \\
\hline 5. What would you do if you had close contact with confirmed cases? & $\begin{array}{l}\text { I will do what I did before the pandemic OR } \\
\text { I will be nervous and don't know what to do } \\
71(4.5)\end{array}$ & $\begin{array}{l}\text { I will report my case } \\
1,511(95.5)\end{array}$ & \\
\hline 6. Sources of update & $\begin{array}{l}\text { Medical sources } \\
173(10.8)\end{array}$ & $\begin{array}{l}\text { Nonmedical sources } \\
1,000(62.4)\end{array}$ & $\begin{array}{l}\text { Combined } \\
69(4.3)\end{array}$ \\
\hline
\end{tabular}

Fig. 2. Association between age and the ability to endure future public health emergencies.

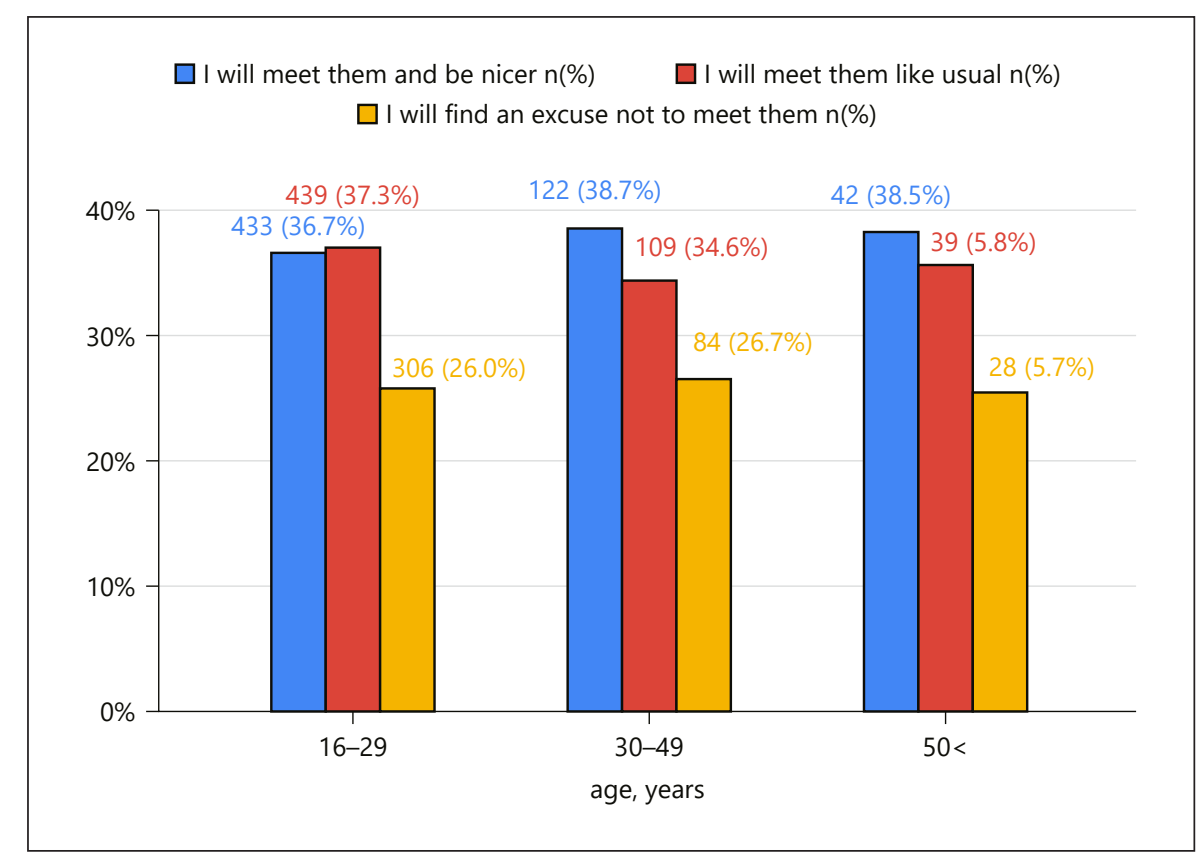




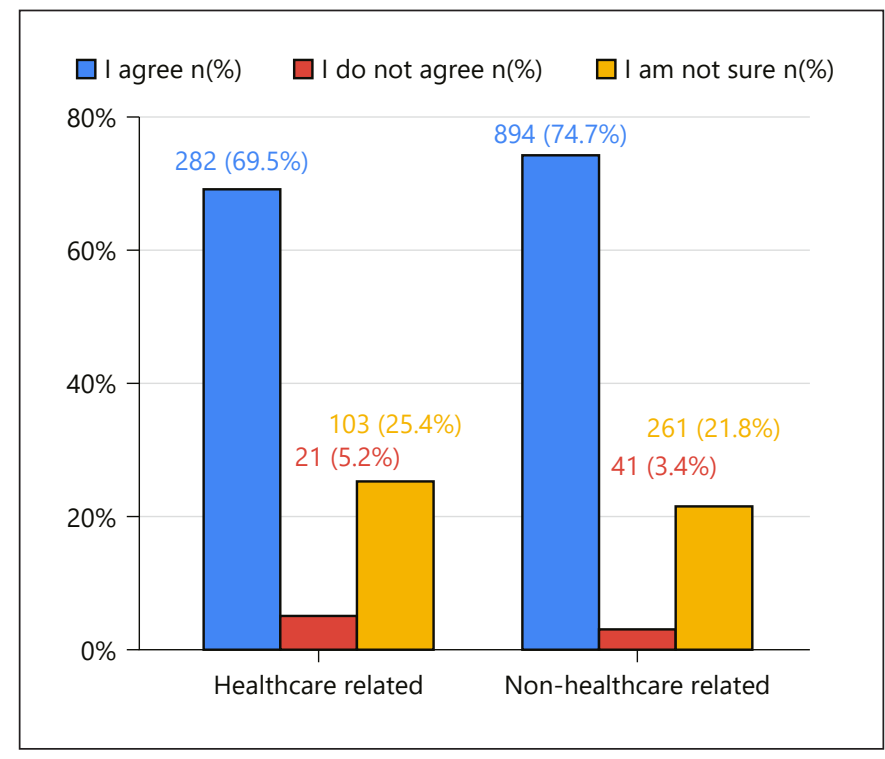

Fig. 3. Association between occupation and do you think COVID-19 will be successfully controlled.

acquired their information from nonmedical sources, while only 173 respondents (10.8\%) relied purely on medical sources such as Medscape or PubMed. Furthermore, we tried to evaluate certain correlations in our study. On assessing correlations between age-groups and attitudes, we found that most participants in all agegroups had felt more capable of enduring public health emergencies in the future ( $p=0.002)$ (Fig. 2). In addition, all age-groups also showed a positive attitude toward meeting someone with COVID-19 infection, where the majority answered they would meet them and be nicer or meet them like usual ( $p=0.929)$.

Upon assessing correlations between occupation (healthcare-related and non-healthcare-related) and believing COVID-19 will finally be controlled, we found similar results. Majority, 894 (74.7\%), of non-healthcare workers and $282(69.5 \%)$ of healthcare workers agreed that it will be controlled ( $p$ value $=0.074)($ Fig. 3$)$.

With our results, we also tried to evaluate if there were any differences in practice between male and female individuals if they ever developed fever and dry cough. A slightly greater percentage of women 1,308 (93\%) said they would think through it logically, whereas 167 (88.8\%) men answered the same $(p<0.010)$.

Both groups, males and females, also responded positively when asked what they would do if they ever came in contact with confirmed cases. 173 (92\%) males and 1,338 (96\%) females answered they would report their case $(p$ value $=0.014)$.

Knowledge, Attitude, and Practice toward COVID-19 among UAE Residents

\section{Discussion}

On the first day of this study, the May 31, 2020, the total number of confirmed COVID-19 cases in the UAE was 34,557 , the total number of recoveries was 18,196 , and the total number of deaths was 264 . As of the last day of this study, the June 31,2020, the total number of cases in the UAE was 41,990 , the total number of recoveries was 27,049 , and the total number of deaths was 288 [5]. Understanding the trend and pattern in between is necessary to calculate the impact of the novel coronavirus on the health system as well as the economy. To the best of our knowledge, this is the first study of its kind that has been conducted in the UAE.

The overall knowledge score about COVID-19 among our study participants was $71 \%$, with a mean score of 4.26 (SD 1.24; range 0-6). Interestingly, the results of this study showed us that 993 (62\%) respondents believed there is a viable vaccine for COVID-19. It is worth noting that though multiple research centers around the world are in the work of developing a vaccine, there was no vaccine safe to use for the public when the questionnaire was being conducted. Additionally, only 489 $(30.5 \%)$ participants understood that people, in general, are susceptible to COVID-19 infection, whereas the overwhelming majority believed it was either the elderly or people with pre-existing conditions. This misunderstanding can probably be addressed via appropriate health education.

Overall, this study demonstrated an adequate knowledge score. Factors that could have contributed to this include the government's efforts in raising awareness through campaigns [6], accessible information online, and a high educational level with $79 \%$ of the respondents having attended college. Our findings of an overall adequate knowledge score are consistent with similar studies carried out in other countries [7-9].

The attitude score was $78 \%$, which reflects a positive attitude among the population. There was a marginal difference between the overall female versus male scores, healthcare versus non-healthcare workers, and different levels of education for all the attitude questions. Finally, the calculated practice score was $76 \%$.

In a similar KAP study carried out in Sudan with demographics like ours, where majority of participants were predominantly young females, they found that higher knowledge scores were associated with better practices and a positive attitude among participants. Their findings also showed that young citizens, particularly women, had good KAP toward COVID-19 [10]. 
In regard to most participants $(62.4 \%)$ choosing nonmedical sources to stay updated on the matter, these sources range from local authorities, local news and newspapers, social media platforms, to friends or family. It is very important to advise users however to only consider reliable Websites. Moreover, the results showed that some respondents still preferred herbal remedies such as garlic $(13 \%)$ or honey with ginger $(23 \%)$. Although Chinese researchers conducted a meta-analysis for available guidelines for traditional herbal remedies that help in guiding treatment measures of COVID-19, this still requires further clinical evidence to support its efficacy [11].

With regard to practices to safeguard from COVID-19, participants who were in college or obtained a higher degree had a practice score of $76.88 \%$ compared to $74.72 \%$ scored by participants with less education. This contrasts with the knowledge scores of both groups, in which people who were in or graduated college scored $72.89 \%$, while people who completed high school and less scored $66.52 \%$.

Surprisingly, when it came to practices between healthcare workers or non-healthcare workers, both groups scored 76\%. Assessing COVID-19 knowledge however showed that participants in healthcare-related jobs scored $77.75 \%$, whereas participants in non-healthcare-related jobs scored only $69.46 \%$.

A few limitations were faced during the study; female UAE residents proved to be more adamant to fill the survey than males as $88 \%$ of participants were female. And $73.5 \%$ of participants belonged to the age-group of 16-29 years seemingly because the younger age-groups are the most active on social media and use smartphones more frequently.

\section{Conclusion}

As per the main principle of epidemiology, public education is one of the key tools to spread appropriate knowledge, positive attitude, and sound practices. The study results show a positive attitude, good knowledge, and good practice among the general population in the UAE. However, as not $100 \%$ of participants answered all the questions correctly, it is still encouraged to maintain continuous efforts to spread awareness and public health education across all platforms, virtually as well as in real life. The results of this study can be used to customize future awareness campaigns while targeting the desired population, as well as to direct further research about COVID-19 in the country, and specifically educating the public about the nature of the virus, who the susceptible groups are, and where the world stands when it comes to a vaccine against COVID-19 today and advising individuals who rely on social media to acquire updates on the virus to refer only to reliable accounts.

\section{Acknowledgments}

We would like to extend our gratitude to Dr. M.Z. for his great help and assistance with analyzing the data and to our supportive supervisor Dr. D.S.A. We also wholeheartedly appreciate all the candidates who took the time to fill our survey.

\section{Statement of Ethics}

The study obtained the ethical approval by the Emirates Institutional Review Board for COVID-19 Research Committee Number DOH/CVDC/2020/1342, dated on July 13, 2020. The participants were not compensated, and all participants gave a digital consent form, which mentions the objective, and the method of the research conduction would be given to the participants before proceeding with the questionnaire. All participants were insured for anonymity and confidentiality.

\section{Conflict of Interest Statement}

The authors state that this research was held in the absence of any commercial or financial relationships that could be labeled as a potential conflict of interest.

\section{Funding Sources}

The authors have not received any funding or benefits from industry or elsewhere to conduct this study.

\section{Author Contribution}

All authors contributed to the survey design. L.L., A.H.A., A.A., and Z.S. analyzed the results. All authors contributed to the writing of the manuscript. All authors listed have made significant contributions to the study and approved it for publication. 


\section{References}

1 Cennimo DJ, Bergman SJ, Olsen KM. Coronavirus disease 2019 (COVID-19). Medscape, in infectious diseases under drugs \& diseases. 2020. Retrieved from: https://emedicine. medscape.com/article/2500114-overview.

2 World Health Organization. Timeline: WHO's COVID-19 response. 2020. Retrieved from: https://www.who.int/emergencies/diseases/novel-coronavirus-2019/interactivetimeline\#! Accessed 2020 August 26.

3 National Emergency Crisis and Disasters Management Authority. UAE coronavirus (COVID-19) updates. 2020. Retrieved from: http://covid19.ncema.gov.ae/en Accessed 2020 August 26.

4 Dr. Tedros Adhanom Ghebreyesus. WHO Director-General's opening remarks at the media briefing on COVID-19: 16 March 2020. WHO website. 2020. Retrieved from: https:// www.who.int/dg/speeches/detail/who-director-general-s-opening-remarks-at-the-media-briefing-on-covid-19---16-march-2020 Accessed 2020 July.
5 In United Arab Emirates under Countries. 2020. Retrieved from: https://www.worldometers.info/coronavirus/country/united-arabemirates/ Accessed 2020 August 26.

6 Ministry of Health \& Prevention. Novel Coronavirus (COVID-19) UAE. 2020. Retrieved from: https://www.mohap.gov.ae/en/ AwarenessCenter/Pages/COVID-19.aspx Accessed 2020 July.

7 Al-Hanawi M, Angawi K, Alshareef N, Qattan AMN, Helmy HZ, Abudawood Y, et al. Knowledge, attitude and practice toward COVID-19 among the public in the kingdom of Saudi Arabia: a cross-sectional study. Front Public Health. 2020;8:217.

8 Erfani A, Shahriarirad R, Ranjbar K, Mirahmadizadeh A, Moghadami M. Knowledge, attitude and practice toward the novel coronavirus (COVID-19) outbreak: a population-based survey in Iran. 2020. Retrieved from: https:// www.researchgate.net/publication/ 340457803_Knowledge_Attitude_and_Practice_toward_the_Novel_Coronavirus_ COVID-19_Outbreak_A_Population-Based_ Survey_in_Iran.
9 Alzoubi H, Alnawaiseh N, Al-Mnayyis A, Abu-Lubad M, Aqel A, Al-Shagahin H. COVID-19: knowledge, attitude and practice among medical and non-medical university students in Jordan. J Pure Appl Microbiol. 2020;14(1):17-24.

10 Altayb Mousa KNA, Saad MMY, Tayseer Bashir Abdelghafor M. Knowledge, attitudes, and practices surrounding COVID-19 among Sudan citizens during the pandemic: an online cross-sectional study. Sudan J Med Sci. 2020. Retrieved from: https://knepublishing. com/index.php/SJMS/article/view/ 7176/12817.

11 Ang L, Lee HW, Choid JY, Zhang J, Soo Lee M. Herbal medicine and pattern identification for treating COVID-19: a rapid review of guidelines. 2020. Retrieved from: https:// www.sciencedirect.com/science/article/pii/ S2213422020300391. 